\title{
IDENTIFYING THE CRITERIA AND THEIR PRIORITIES FOR LOCATING BANK BRANCHES IN TURKEY
}

\author{
Ayfer Başar, Özgür Kabak, Y. İlker Topçu \\ Istanbul Technical University, Industrial Engineering Department, \\ Maçka Campus 34357, Maçka, Turkey \\ E-mail: ayferbasar@gmail.com,kabak@itu.edu.tr, topcuil@itu.edu.tr
}

\begin{abstract}
Although technology has improved and distribution channels such as credit cards, mobile-internet banking, operation centers, automated teller machines, point of sales etc. have become alternative opportunities for reaching bank services, the branch offices are still important for the banks to gain new customers and keep in touch with them. Therefore the problem of selection best location for branches is a fundamental topic for banks to reach their goals. Finding the best location for bank branches depends on a number of distinct measures which differ according to the banks' strategies and vision, customer profile in the potential location and features of the place where the branches will be located. This paper presents a methodology to find the criteria and their priorities for location planning of Turkish bank branches in Istanbul. For this aim, firstly, a number of criteria are selected by the help of a detailed literature review and expert judgments. Subsequently priorities of these criteria for four different types of bank branches are identified based on expert judgments using pairwise comparisons. The priorities will be used in a new mathematical model developed to decide the best branch locations of a Turkish national bank in Istanbul.
\end{abstract}

Keywords: bank branches, location, criteria, priorities, pairwise comparison.

\section{Introduction}

As a result of developments in economics, banking sector has become one of the fundamental businesses in Turkey in the recent years. Since competition in banking has increased, profitability has become a major goal for both public and private banks. Therefore, banks have to carry out different gainful strategies such as decreasing costs by the help of technological developments (e.g. mobile and internet banking, credit cards, automated teller machines etc.). On the other hand, branch offices are still one of the most important channels to reach available and potential customers and make them loyal for banks by means of direct communication.

Growth in population and urbanization in Turkey forces the banks to increase the number of their branch offices in service to reach new customers. For instance, according to the statistics of The Banks Association of Turkey, the number of total domestic bank branches has increased by $7.8 \%$ from 10,159 to 10,952 in the 2013 . Therefore, locating the new branch offices in the best place is one of the important decision problems for Turkish banks, as well as for the banks in the other countries. 
There are several studies in the literature about finding the best place for bank branches. Boufounou (1995) used regression analysis to show that total population in terms of gender and age, average household size, population growth rate, domestic per capita income, number of firms in terms of sector, position of competitor banks were important criteria about the bank branch performance in Greece. Abbasi (2003) developed a decision support system for locating bank branches in Jordan and used population, income level, cultural characteristics, number of firms, total deposit, growth potential and competitive situation as variables in the proposed model. Zhao et al. (2004) emphasized that financial indicators, demographic characteristics, customer segmentation, position of competitor banks and means of access of the potential points had to be considered for bank branches locations. Cinar (2009) have identified five main criteria as demographic, socioeconomic, banking indicators, recruitment in accordance, and trade potential, which include 21 sub criteria.

Literature review shows that different criteria and mathematical models are used for the problem of bank branch location where common criteria does not exist. This study proposes a novel approach to identify the most effective criteria and their priorities to select the best places for different types of Turkish bank branches. According to literature survey transaction volume of potential sites is one of the most important performance criteria of bank branches (Manandhar and Tang, 2002; Cook et al., 2004; Camanho and Dyson, 2005). Therefore this study intends to find out the right criteria effecting transaction volume based on a detailed literature survey and experts' opinions. In addition to the transaction volume, penalty of opening branches nearby to each other, cost of opening a new and closing an available branch are also considered as the other main criteria depending on the experts' judgments. Subsequently priorities of these four main criteria are identified using pairwise comparisons.

\section{Identifying the Criteria}

In order to find out the related criteria for the making location decision of the bank branches in Turkey, firstly, the criteria used in the literature are listed. Population, growth potential, income level, competitive situation and number of firms in the candidate districts were used by Boufounou (1995), Abbasi (2003) and Cinar (2009) to decide the location of branch offices. Moreover; financial indicators, demographic characteristics, customer segmentation, position of competitor banks and easement of access were considered in Zhao et al. (2004).

Furthermore experts' opinions are considered to identify specific criteria for the location problem of bank branches. Necessary information is gathered through an unstructured questionnaire by the help of face to face meetings. Interviews are conducted to five experts working in banking sector as senior executives. Average transaction volume is decided to be the most effective indicator according to the all experts and it is also supported by the literature (Camanho and Dyson, 2005; Portela and Thanassoulis, 2007). Since forecasting the average transaction volume accurately is almost impossible, different criteria are identified depending on literature survey and experts' opinion as given in Table 1. 
ISAHP Article: Başar, Kabak, Topçu/ Identifying the Criteria and Their Priorities for Locating Bank Branches in Turkey

Table 1

Criteria identified for the estimating average transaction volume

\begin{tabular}{|c|c|c|}
\hline Criteria & Proposed Sub Criteria & Related Criteria in the Literature \\
\hline $\begin{array}{l}\text { Number of potential } \\
\text { customers }\end{array}$ & Daytime population & $\begin{array}{l}\text { Demographic characteristics (Min, } \\
\text { 1989; Kaufman and Mote, 1994) }\end{array}$ \\
\hline $\begin{array}{l}\text { Socioeconomic } \\
\text { situation }\end{array}$ & $\begin{array}{l}\text { Education level, number of } \\
\text { houses and summer houses }\end{array}$ & $\begin{array}{l}\text { Literacy rate and education level } \\
\text { (Cinar, 2009) }\end{array}$ \\
\hline Social potential & $\begin{array}{l}\text { Number of education and } \\
\text { entertainment places, hospitals, } \\
\text { parks }\end{array}$ & Social potential (Abbasi, 2003) \\
\hline Commercial potential & $\begin{array}{l}\text { Number of works places, } \\
\text { shopping centers, car parks, } \\
\text { financial institutions, car } \\
\text { services, restaurants }\end{array}$ & $\begin{array}{l}\text { Commercial potential (Meidan, 1983; } \\
\text { Cinar, 2009) }\end{array}$ \\
\hline Competition & $\begin{array}{l}\text { Number of competitors' bank } \\
\text { branches }\end{array}$ & $\begin{array}{l}\text { Number of banks and branches, } \\
\text { position of competitor banks (Meidan, } \\
\text { 1983; Boufounou, 1995, Abbasi, } \\
\text { 2003; Zhao et al., 2004; Cinar, 2009) }\end{array}$ \\
\hline Financial situation & Average household income & $\begin{array}{l}\text { Hosting ratio (Clawson, 1974); } \\
\text { income level (Abbasi, 2003; Zhao et } \\
\text { al., 2004); employee and employer } \\
\text { rate (Meidan, 1983; Zhao et al., 2004; } \\
\text { Cinar, 2009) }\end{array}$ \\
\hline Easement of access & $\begin{array}{l}\text { Ease of travel, accessibility and } \\
\text { proximity to public transport }\end{array}$ & $\begin{array}{l}\text { Easement of access (Min, 1989; Zhao } \\
\text { et al., 2004) }\end{array}$ \\
\hline Growth potential & Growth of total population & $\begin{array}{l}\text { Population growth rate (Boufounou, } \\
\text { 1995; Abbasi, 2003; Zhao et al., 2004; } \\
\text { Cinar, 2009) }\end{array}$ \\
\hline
\end{tabular}

Since data related to daytime population is not provided, number of potential customers of all candidate places is estimated by different criteria affecting daytime crowdedness of the regions which are total population, number of work and education places, financial institutions, and hospitals. Similarly, proximity to public transport is not obtained, therefore depending on transportation network, total distance to the neighbor districts is used as a cost attribute to measure easement of access. On the other hand, after analyzing correlation between criteria values depending on 763 districts in Istanbul; number of houses, parks and restaurants are eliminated since they have high correlation between these criteria and total population, number of car parks and financial institutions, respectively.

According to the experts' judgments, in terms of reaching to more customers, banks give more importance to locate their branch offices in the right places rather than opening same type of multiple branches near each other. Thus, the distance between the potential points becomes another main criterion to avoid opening same type of multiple branches very close to each other. For this aim, opening new branches near each other is decided to be penalized in the proposed methodology. Finally, experts indicate that there is a cost of opening a new branch because of hiring, recruitment, overhead costs etc. Similarly, there is a cost of closing an available bank branch because of losing customers and reputation.

International Symposium of 
ISAHP Article: Başar, Kabak, Topçu/ Identifying the Criteria and Their Priorities for Locating Bank Branches in Turkey

As a result, four main criteria are identified as average transaction volume, distance between branches, cost of opening a new branch, and cost of closing a branch where average transaction volume has 8 sub-criteria given in Table 1.

\section{Finding the Priorities}

Because of data confidentiality in the banking sector, it is not possible to provide actual transaction volume. Therefore, we have to predict transaction volume according to the criteria identified in the previous section and their priorities that reflects their importance to the transaction volume. A weighting method should be used for this purpose. Among different weighting technics, pairwise comparison as in AHP approach is found as the most appropriate method for the particular problem. Focusing on only two alternatives at each time, pairwise comparison gets benefit from expert judgment and gives generally more accurate results compared to the other weighting methods (Malczewski, 1999). Additionally, since decision makers focus on evaluating criteria one another at each time, the results are not affected by the external factors. Therefore, as is also stated in Badri (2001) significant and right benchmarks are obtained by pairwise comparisons. Moreover, the method is applied successfully in different studies of the location literature (Tzeng et al., 2002; Aras et al., 2004; Wu et al., 2007; Fernandez and Ruiz, 2009).

Banks' measures of customer segmentation highly affect their customer profile and the location of the branches. Therefore banks need to open different types of branches to give different types of services to different customer segments. By this way operating cost can be decreased and efficiency of the business process can be increased. The most common types of branch offices for Turkish banks are individual, entrepreneur, corporate and commercial bank branches. Individual branches provide service in strong and busy market with standard transactions presented to every kind of real customers. Entrepreneur branches serve real customers who have banking assets valued at more than a certain amount. Corporate and commercial branches' customers are organizations dealing with generally industrial and business activities. Corporate branches usually serves to small and medium enterprises while the commercial branches serve to high profile companies and holdings. Since the priorities of the criteria differ according to the type of the branch, we find the weights of the criteria for each type.

In order to find the priorities of the criteria for each type of a branch, we conduct a questionnaire to ten experts of bank branch location problem who have experience to work in different banks in Turkey as mid-level managers. The final priorities are identified as in Table 2 and 3.

Table 2

Priorities of main criteria

\begin{tabular}{lcccc}
\hline Sub Criteria & Individual & Entrepreneur & Corporate & Commercial \\
\hline Transaction volume & 0.51 & 0.56 & 0.51 & 0.52 \\
Distance between branches & 0.32 & 0.27 & 0.30 & 0.30 \\
Cost of opening a new branch & 0.10 & 0.09 & 0.12 & 0.12 \\
Cost of closing a branch & 0.07 & 0.08 & 0.07 & 0.06 \\
\hline
\end{tabular}

International Symposium of $\quad 4$

4

the Analytic Hierarchy

Washington, D. C.

Process

June 29 - July 2, 2014 
ISAHP Article: Başar, Kabak, Topçu/ Identifying the Criteria and Their Priorities for Locating Bank Branches in Turkey

Table 3

Priorities of criteria for transaction volume

\begin{tabular}{lclll}
\hline Criteria & Individual & Entrepreneur & Corporate & Commercial \\
\hline Number of potential customers & 0.24 & 0.14 & 0.07 & 0.05 \\
Socioeconomic situation & 0.06 & 0.06 & 0.06 & 0.07 \\
Social potential & 0.08 & 0.08 & 0.07 & 0.06 \\
Commercial potential & 0.16 & 0.18 & 0.39 & 0.44 \\
Competition & 0.12 & 0.14 & 0.12 & 0.10 \\
Financial situation & 0.16 & 0.22 & 0.18 & 0.15 \\
Easement of access & 0.10 & 0.09 & 0.05 & 0.05 \\
Growth potential & 0.08 & 0.09 & 0.06 & 0.08 \\
\hline
\end{tabular}

According to the results in Table 2, transaction volume is the most important main criterion. The most important criteria effecting transaction volume are number of potential customers for individual; commercial potential for entrepreneur, corporate and commercial branches (see Table 3). Priorities of sub criteria are also found: From the perspective of number of potential customers, while total population is the most important factor for individual and entrepreneur branches; number of financial institutions is most fundamental sub criterion for corporate and commercial branches. As a socioeconomic status indicator; education level is more important than number of summer houses for all branch types. Number of education places is the most important sub criterion for individual and entrepreneur branches, while priority of number of hospitals is the highest for the other two branch types as a social potential sub criterion. Finally for commercial potential, number of work places has highest priority for all branch types.

\section{Conclusions and Future Studies}

In this paper, an approach to identify the criteria and their importance for making decision of Turkish bank branches' location planning in Istanbul is presented. As a further study a new mathematical programming model can be developed based on the priorities found in this study to determine the exact locations of the branches. A research on solving this mathematical model for a large sized real life problem (Eg. for Istanbul with 763 districts) will be a challenge.

\section{Key References}

Abbasi, G.Y. (2003). A decision support system for bank location selection. International Journal of Computer Applications in Technology, 16, 202-210.

Boufounou, P.V. (1995). Evaluating bank branch location and performance: A case study. European Journal of Operational Research, 87, 389-402.

Cinar, N. (2009). A decision support model for bank branch location selection. World Academy of Science, Engineering \& Technology, 60, 126-131.

International Symposium of 5

the Analytic Hierarchy 